\title{
Influence of Data Analysis, Entrepreneurial and Business Skills on Information Technology Firms: A Dynamic Capabilities Approach
}

\author{
Michail N. Giannakos, Patrick Mikalef and Ilias O. Pappas \\ Norwegian University of Science and Technology, Trondheim, Norway \\ michailg@ntnu.no; patrick.mikalef@ntnu.no; ilpappas@ntnu.no
}

\begin{abstract}
In the contemporary business environment, the innovation and quality of the Information Technology (IT) industry's products and services depend to a great extent on the knowledge, ability and talent applied by IT professionals. IT professionals' skills and capacities to integrate, build, and reconfigure resources in the continuously evolving business environments is critical. In particular, inefficiencies usually come from the lack of skills or IT professionals' inability to apply them in a way that allows a firm to adapt and evolve concurrently with business demands. With these challenges in mind, this paper presents a study conducted with 72 IT professionals to test the importance that data analytics, entrepreneurial, and business skills have in enhancing employees' dynamic capabilities and ultimately their perceived work performance. This study confirms that there is an important association between the three types of skills and employees' ability to effectuate action that helps a firm evolve. By fostering such a capacity which is critical in modern day firms, their perception about their work performance is ultimately affected.
\end{abstract}

\section{Introduction}

Firms' performance and competitiveness is heavily dependent on its human capital (e.g., employees' skills and competencies). Human capital cannot be fully controlled by the company and includes employees' knowledge, skills, values, needs and attitudes in the work environment [12]. Organizations need to recruit, develop and retain talents in order to improve firm's overall productivity [3]. Human capital is critical for innovation, especially in the area of Information Technology (IT) where employees is organization's most valuable resource [3]. Colomo-Palacios et al. [8], also identified human capital as one of the main issues in the IT industry. In fact, one of the IT industry's concerns is related to the development of its professionals in order to increase the quality and innovation of its products and services [45].

The overall performance of a firm and its adaptiveness to the environment depends to a great extent on IT professionals' knowledge and expertise towards the software development process [37] as well as their non-technical skills (e.g., project management) [16]. Prior research guides how to manage the organizations [23], and highlights the importance of both technical and non-technical skills and competences $[16,34]$. Prior studies however do not incorporate skill and value perceptions related with the 21st century technological developments [53], like big data, internet of things, ubiquitous technologies, and entrepreneurship amongst others $[4,9,35]$. Despite the fact that those technological developments provide a way forward for solving the global challenges of the 21 st century, building sustainable development, and advancing human welfare [53], it is still unclear how those skills might benefit IT professionals' evolvement and performance. This paper complements prior work by offering guidance in this area.

While much emphasis of the Information Systems (IS) domain has been placed on how firms utilize their resources and capabilities to remain competitive throughout turbulent and uncertain conditions [31], there is limited research on the individual, employee level. An article of Teece [46] has focused on the micro-foundations that surround the development of dynamic capabilities. This paper takes an in-depth view into the firm and recognizes the importance that up-to-date skills and knowledge have on the sustainable enterprise. Nevertheless, there have been very few empirical studies that explore the relationship of such micro-foundations and dynamic capabilities, and to the best of our knowledge, very limited in number in the IS domain [10].

Therefore, in this study we extend the DynamicCapability View (DCV) [13] by examining how selected important 21st century skills (namely: data analytics, entrepreneurial and business skills) influence their development and ultimately lead to increased levels of perceived work performance. To this end, we employ an empirical study drawing data from 72 IT professionals to test our hypotheses. The paper contributes to the literature first, by offering empirical evidence on the important role of data analytics, entrepreneurial and business skills on the development of dynamic capabilities, and second, by exploring the role of dynamic capabilities of IT professionals in 
today's demanding and continuously evolving IT firms.

The rest of the paper is structured as follows. In the next section we present the related work and theoretical foundation upon which the conceptual research model is built. In section 3 the methodology is outlined, and in section 4 the findings of the study are presented. In closing, section 5 provides a discussion on research directions and areas of future interest

\section{Background and Conceptual Model}

Resource-based theories propose that firm's success depends on how well the firm manages its resources, especially the resources related to human capital [39]. Resent resource-based studies suggest firms will benefit from assessing and strengthening the skills and competencies of their employees [34]. According to the resource-based theories, rare, valuable, hard to imitate and hard to substitute resources are ess ential but not sufficient components to the competitive advantage of the firm [1]. Several studies have used resource-based view (RBV) to investigate the ability of IT professionals to utilize various IT skills to enable organizational changes and achieve greater organizational effectiveness [51]. Common perspective for those studies is accumulating VRIN (Valuable, Rare, Inimitable, and Nonsubstitutable) resources to enhance firm's competitive advantage.

These studies are in alignment with recent literature $[20,52,55]$; since competitive advantage is highly related with the combinability and re-configurability of the key resources and skills of firm's workforce. Similarly, IT-graduates with certain skill and competences must develop the ability to combine or reconfigure these re-sources, in order to achieve competitive advantage and increase their performance [15]. Skills and competencies are measurable elements forming organization's human capital, but resourcebased scholarship has offered little concrete guidance [15] on the importance of dynamic-capabilities in firm's workforce. Hence, further research in the intersection of professionals' skills and dynamiccapabilities is required. Especially in the IT industry, where the development of innovative IT-related services and applications require cross-functional collaboration and adaptation to various needs [21], dynamic-capabilities is the lynchpin for firm's competitive advantage.

Although the RBV has emerged as one of the substantial theories in the intersection of strategic and resource management, $\mathrm{RBV}$ can only explain the roles of IT-skills in relation to producing competitive advantage when these skills can be viewed as the static resources an IT department possesses. Scholars extend
RBV by incorporating dynamic characteristics and form the DCV [10]. DCV clarifies that mechanisms are needed to recon-figure and integrate the extant resources to sustain competitive advantage in the continuously evolving environment. Teece [46] define dynamic capabilities (DC) as ability to integrate, build, and reconfigure internal and external resources to address rapidly changing environments. Hence, in the IT-industry where professionals face dynamic and fastchanging environments, DCV explains competitiveness more effectively than RBV [13, 54].

Hard skills, like software development, architecture and maintenance are essential for professionals to take on an entrepreneurial role and focus on innovation. However, the complete spectrum of needed skills for IT professionals is determined by the tasks that are required in their work environment [25], and as the complexity of technology increases, the skills of related professionals must also increase [55]. Thus, in addition to IT hard skills, 21st century IT professionals must pose a robust understanding of data analys is [22], entrepreneurship and business [52]. These skills allow them to utilize resources in order to gain innovative outcomes and competitive advantages. Today's challenges of IT industry faced by IT professionals go beyond solving technical problems and the expected skillset requires knowledge in relation to business functionality, decision making strategy and evolving environment, especially in an increasingly turbulent business and technological context [55]. In this context, DC are regarded as a transformer for converting resources into improved performance [26]. $\mathrm{Wu}$ [54] demonstrates the central role of dynamic capabilities that mediate between entrepreneurial/business res ources and performance.

IT-related skills, especially the skills possessed by the IT professionals, can be viewed as complimentary to VRIN resources. If IT personnel have adequate set of skills, they can combine those skills with VRIN resources to improve or adjust IT applications efficiently and effectively in order to in-crease the quality and innovation of the produced products and services [42, 51]. Kim et al. [21] describe IT expertise skills as "professional skills and knowledge of technologies, technology management, business functions, and relational (or interpersonal) areas necessary for IT staff to undertake assigned tasks effectively" (p. 492). Related work in the area of technical skills and abilities (hard skills) of IT professionals based on their training and expertise in specific technical areas, and these skills can advance the development or configuration of IT-related services [15]. In order to develop IT-applications that satisfy today's increased demands, IT professionals must have the abilities to communicate with the end user and 
understand the tasks of other functions in addition to their technical skills [52]. In this study, we combine DC with skills related with data analytics, entrepreneurship and business, to offer an empirical evidence about the critical role of those emerging skills through the established DCV framework.

We propose our research model in Fig. 1. In the model, the dynamic capabilities of IT professionals are regarded as an important predictor of their work performance. Further, their dynamic capabilities mediate this association and are influenced by their data analysis, entrepreneurial and business skills .

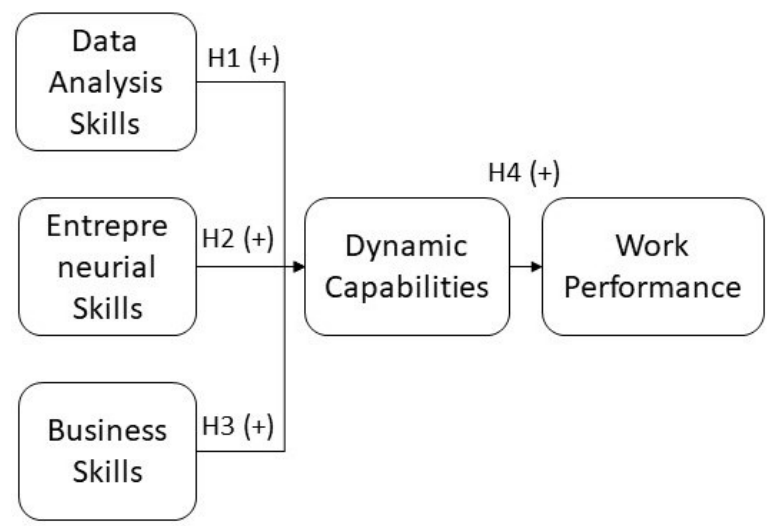

Figure 1. Research Model and Hypotheses

Professionals with strong data analys is skills are the cornerstone for a company to move from competitive parity to competitive advantage [22]. Data analysis skills are distinct from IT skills that are found to complement general technology use [19]. To effectively leverage data, firms need to have competent IT professionals who can continuously monitor and learn from the real-time data about their business and inform future decisions and strategies. Those IT professionals should have analytical thinking, ability to handle large amounts of data, knowledge of analytics techniques and statistical modelling, as well as the capacity to tackle problems with a data-driven approach [9]. Those skills differ from typical IT skills (or partially overlap), someone will master in the undergraduate or even graduate level of an IT degree [40, 49].

As such, the value of data analytics skills does not lie in IT resources per se, although their availability is a prerequisite, but rather, on the process of seamlessly integrating these skills and knowledge into the firm. Thus, contemporary enterprises are in great need for IT professionals who have both the ability to manage and process data as well as understand firm's needs and provide the needed knowledge to guide data-driven decisions. However, those IT professionals with good data analytics skills are in a better position to enable knowledge extraction and management, which is connected with high levels of DC [30]. Thus, we formulate the following hypothesis:

H1: IT professionals with high data analytics skills are more likely to contribute towards enhancing a firms' dynamic capabilities.

The consideration of entrepreneurship as the result of a certain set of skills and cognitive processes is widely accepted today [27]. Although there is much research needed in order to understand the way in which those individual entrepreneurial perceptions and processes are formed; skills and beliefs regarding entrepreneurship have found to be critical for firms [7]. Especially, IT industry requires entrepreneurial skills to discern and utilize resources at the periphery in order to gain innovative outcomes and competitive advantages [21]. In a projects-oriented industry, like IT, it is critical for firms to pursue innovation-based competitive strategy, in order to exploit unique valuecreating opportunities, which in turn lead to higher levels of service innovation [41].

Entrepreneurial skills are associated with higher personal attraction (i.e., personal evaluation) and subjective norms, possessing those skills could make individuals feel capable to start a new initiative or firm [44]. Entrepreneurial skills allow an individual to update his beliefs about his entrepreneurial aptitude, and provide him with the knowledge of how difficult it is to get a project or initiative off the ground [14]. As with any other industry, in IT, entrepreneurial skills are related with sensing, seizing, and transforming, necessary qualities for an individual to attain and sustain dynamic capabilities [47]. Thus, we propose the following hypothesis:

H2: IT professionals with high entrepreneurial skills is more likely to contribute towards enhancing a firms' dynamic capabilities.

Training IT professionals with business skills is driven by practical issues and demands [52]. Demands from the IT industry is evident from both IT personnel job advertisements but also the guidelines for IT curriculum design [40, 49]. For example, after analyzing job advertisements for IT professionals (e.g., software engineers) across two decades; it became clear that business skills, if one of the most important knowledge areas for hiring IT personnel [52]. Along the same lines, IT curriculum guidelines - developed by the Association for Computing Machinery (ACM), the Association for Information Systems (AIS) and the IEEE-CS [40, 49] - suggested that IT professionals should be equipped with: business skills and business domain fundamentals. Business skills and business domain fundamentals includes leadership, collaboration and communication skills as well as knowledge and skills regarding general business 
models, key business specializations, and the evaluation of business performance [52]. Hence, we propose the following hypothesis:

H3: IT professionals with high business skills is more likely to contribute towards enhancing a firms', dynamic capabilities.

Dynamic capabilities improve the effectiveness, speed and efficiency of organizational responses to environmental turbulence [19], which ultimately strengthens performance. To deal with a rapidly changing environment in the IT (or IT related) industry, resources need to be able to transformed or evolved. In the IT industry, IT professionals is firm's most valuable resource [43], hence IT professionals' ability to transform is critical. At the same time, this transformation needs to happen in a cost-effective manner [26]. As a result, the dynamic capability of IT professional, which can be defined as their ability to integrate, build, and reconfigure competencies in rapidly changing environments [46], is directly connected with performance and competitive advantage. Similarly, Wu [54] depicts the central role of dynamic capabilities that mediate between entrepreneurial/business resources and performance. By perceiving themselves as being capable of contributing towards the reconfiguration of the way a firm works, it is argued that employees will consider themselves as more competent in their work performance. Therefore, since our study focuses on the IT professionals, we hypothesize that:

H4: IT professionals who contribute towards enhancing a firms' dynamic capabilities are more likely to have high perceived work performance.

\section{Research Methodology}

\subsection{Data collection and participants}

To actualize the objectives of this study a custombuilt questionnaire was developed and sent to respondents to fill out electronically (online questionnaire). Our target population consisted of IT graduates from Norway's primary university for technological education, with respondents filling out the questionnaire required to be in an active IT position. The survey was con-ducted between February and March 2016. In order to recruit participants, we distributed the online survey via the IT graduates' alumni mailing list. A raffle was created with gift cards as a reward to the participants. In total, 72 responses were gathered.

The sample consists of 63 men $(87.5 \%)$ and 9 women $(12.5 \%)$, with relatively long experience in the IT industry, which range from 2 to 33 years with an average of 13.21 years (S.D.: 7.35 years). Although the participants of the study had formal IT education and hold IT positions, there is a variation in their expertise and job titles; in particular, 16 are developers (e.g., software engineer, mobile developer), 6 directors (e.g., CTOs, strategy directors, business development), 14 project managers, 21 IT consultants, 8 software architects, 3 in R\&D positions and 5 with responsibilities in various stages. The majority of firms operated in the IT sector $(54.2 \%)$, with companies from oil and gas (9.7\%) and telecommunications $(9.7 \%)$ following, there was also a small proportion of firms from utilities, consumer goods and healthcare (approx. 3-5\% from each sector). The vast majority $(59.7 \%)$ belonged to SME size-class (1-249 employees), with $40.3 \%$ being large enterprises (250+ employees). More specifically, from the SME grouping, micro firms (0-9 employees) accounted for $15,3 \%$, small firms (10-49 employees) for $23,6 \%$, and medium-sized (50-249 employees) firms for 20,8\%. The majority of the firms were active in the national level $(91.7 \%)$ with most of them being also active in the inter-national arena $(65.3 \%)$.

\subsection{Measures and data analys is}

The questionnaire comprised of three parts. First the respondents were presented with different questions about their demographics and personal work experience, followed by the second part which included questions in relation to the size, orientation and focus of their firm, the third part included measures of the constructs related with their Data Analysis Skills (DAS), Entrepreneurial Skills (ES), Business Skills (BS), Dynamic Capabilities (DC) and Work Performance (WP) as those were identified in the literature. The survey included reflective scales for all the constructs that were used in this study with a seven-point Likert-type scale. The operational definitions of all constructs are presented in table 1 (top of the next page), along with their source in the literature. The appendix presents the detailed items used to measure the constructs.

In this study we employ Partial Least Squares (PLS) path modeling in order to validate the causal relationships amongst variables as defined in the research model. The selection of the PLS regression was based on the ability to incorporate a network of causal relationships through latent variables with a relatively small dataset in comparison with the Structural Equation Modeling (SEM) technique. We select the Smart PLS software which also allow for validity and reliability testing. The minimum amount of observations according to Smart PLS documentation is ten for each of the hypotheses; thus the sample of 72 participants surpasses this threshold. 
Table 1. Operational Definitions of the Constructs

\begin{tabular}{|l|l|c|}
\hline \multicolumn{1}{|c|}{ Construct } & \multicolumn{1}{|c|}{ Operational Definition } & Source \\
\hline Data Analysis Skills (DAS) & $\begin{array}{l}\text { DAS is the degree to someone's capacity to make sense, extract } \\
\text { intelligence and make decisions from big data. }\end{array}$ & [50] \\
\hline Entrepreneurial Skills (ES) & $\begin{array}{l}\text { ES indicates how confident respondents are in their possession of a } \\
\text { high-enough level of certain skills related to entrepreneurship (e.g., } \\
\text { feel capable to start a firm, higher personalattraction). }\end{array}$ & {$[27]$} \\
\hline Business Skills (BS) & $\begin{array}{l}\text { BS is the degree to someone's capacity to understand business } \\
\text { functions, problems, needs,policies and plans. }\end{array}$ & {$[6]$} \\
\hline Dynamic Capabilities (DC) & $\begin{array}{l}\text { DC is the degree to someone's capacities to integrate, build, and } \\
\text { reconfigure internal and external resources / competencies to address } \\
\text { and shape rapidly changing environments. }\end{array}$ & {$[46]$} \\
\hline Work Performance (WP) & $\begin{array}{l}\text { WP is the degree to which employees are indicating their } \\
\text { performance. }\end{array}$ & {$[24]$} \\
\hline
\end{tabular}

\section{Empirical Results}

\subsection{Measurement model}

We employ partial least squares (PLS) path modeling techniques to put the conceptual model to test. The software package smartPLS was used to perform both instrument validation and structural path modeling [36]. Formative constructs (as opposed to reflective ones) are not subject to reliability and internal consistency tests since these tests are meaningless for variables of this nature [20]. Unlike reflective constructs which are usually viewed as producing a behavior that is captured by its indicators; formative constructs are formed by their indicators, and therefore have inversed causality. Since formative constructs are composed by their indicators, omitting an item may result in the omission of part of the construct [38]. In our analysis, we make use of first-order formative constructs since the underlying notions that are measured are composed of various elements that are not necessarily inter-related. According to Diamantopoulos et al. [11], the validity of formative measures can be assessed by examining if item correlation is significant on the construct and there is absence of multicollinearity. However, researchers agree that despite construct validity being increased by removing items, content validity is severely affected by doing so [33]. As note by Mackenzie et al. [29], dropping an item from a formative-indicator model may omit a unique part of the conceptual domain and change the meaning of the variable, because the construct is a composite of all the indicators (p. 712). Hence, the validity relies on the development of these formative constructs.

To ensure multicollinearity is not present in our formative construct measurements, the variance inflation factor (VIF) statistic was computed. General statistics theory suggests that multicollinearity is a concern if the VIF is higher than 10; however, with formative measures, multicollinearity poses more of a problem [33] (p641). Hair et al. [18] suggest a more conservative criterion of VIF at 5. None of the VIF values were below this benchmark, suggesting that multicollinearity is not a threat in this dataset.

In accordance with suggestions by Becker et al. [2] and Hair et al. [18] in order to assess whether some indicators should be eliminated, we first examined the weights of the first-order factor on the second-order factor. The importance of examining this association lies in that first-order constructs represent actionable drivers of the higher-order construct, and should therefore be significantly related (relative importance). Since not all weights were significant, we proceeded to analyzing the formative indicators outer leadings (absolute importance). All items corresponding item leadings were relatively high (above the threshold of 0.5 ), therefore there was no need to omit any indicators. Additionally, we established discriminant validity by testing that construct correlations that comprise the higher-order construct are below the threshold of 0.7 [5]. All our constructs have correlations below this threshold, with the greatest being 0.559 .

\subsection{Structural model}

For the structural analysis, we employed a Partial Least Square Structural Equation Modeling (PLSSEM) analysis using the software package SmartPLS 3. We first employed the PLS algorithm in or-der to obtain path weights and then performed a bootstrap analysis in order to assess the significance of paths using 5.000 bootstrap samples in Figure 2 (next page), path coefficients and notations representing the level of significance are presented.

Results of the empirical analysis supported all our four hypotheses. Specifically, data analytics skills have a positive impact on dynamic capabilities $(b=0.396, p<0.001)$, meaning IT professionals with 
high level of data analytics skills are more likely to have high level of dynamic capabilities (H1 supported). We also find that entrepreneurial skills have a positive impact on dynamic capabilities, thus confirming $\mathrm{H} 2(\mathrm{~b}=0.244, \mathrm{p}<0.01)$. This means that IT professionals with high level of entrepreneurial skills are more likely to have high level of dynamic capabilities too. The same found to apply when IT professionals have high level of business skills (H3 accepted) $(b=0.215, p<0.01)$. This means that the higher the business skills are for an IT professional, the greater dynamic capabilities this professional has. The explanatory power of the model is quite high, with the coefficient of determination (R2) being 0.373 , thus explaining $37.3 \%$ of variance. DC were found to positively impact work performance, thus confirming $\mathrm{H} 4(\mathrm{~b}=0.576, \mathrm{p}<0.001 \mathrm{R} 2=0.332)$.

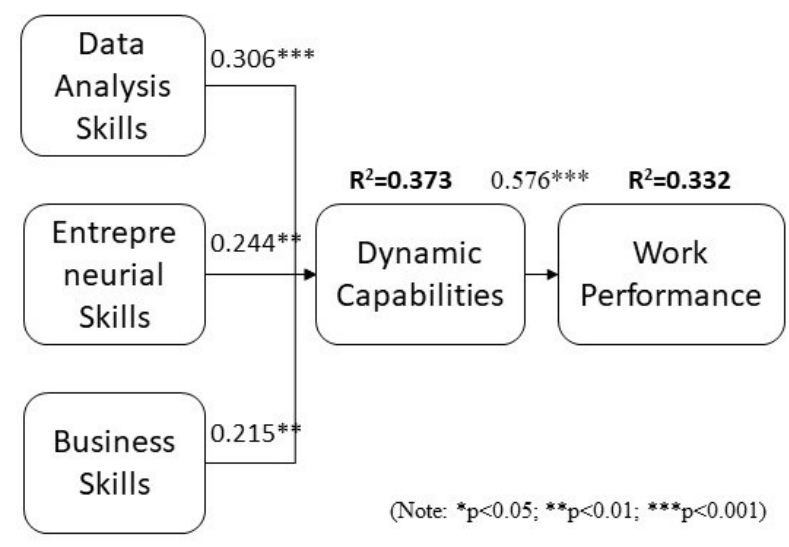

Figure 2. PLS measures for structural model

\section{Discussion and conclusions}

The present study extends the DCV by examining how selected important 21 st century skills influence professionals' development and shape firms' competitiveness. In particular, building on DCV and 21 st century skills a conceptual model is created in order to identify the role of data analytics, entrepreneurial and business skills in IT firms' dynamic capabilities and performance. The model includes five constructs, that is the three types of skills, dynamic capabilities and work performance. By employing the model to IT firms we collected data from 72 IT professionals and test the proposed model. The findings indicate that there is an important association be-tween the three types of skills and employees' ability to effectuate action that helps a firm evolve. In addition, by fostering such a capacity which is critical in modern day firms, their perception about their work performance is ultimately affected.
Developing various skills for IT firms has gained enormous attention from executives, as noted by Luftman et al. [28] in the Society for Information Management. Rather than focusing on traditional soft and hard skills for general employees, we targeted IT professionals and examined factors related with the 21 st century technological developments, like big data, internet of things, ubiquitous technologies, and entrepreneurship amongst others. Unlike previous research which focused on skills as static characteristics of the employee, this study considers the state-of-the-art skills and their contribution to firms' competitiveness in a more dynamic and realistic manner by utilizing DCV.

The four proposed hypotheses were supported by the data and verified our initial conceptions. Our empirical results provide several key findings. First, data analysis skills have strong impact on firm's dynamic capabilities. It does make sense because data analysis skills include analytical thinking, ability to handle large amounts of data and professionals' capacity to tackle emerging problems with a datadriven approach [9]; qualities associated with firm's dynamic capabilities base. For example, in most of IT firms reconfigure and integrate the extant resources to sustain competitive advantage happens in a datadriven manner, since in many cases there are few previous examples and knowledge in these rapidly changing environments. Second, entrepreneurial skills have also strong impact on firm's dynamic capabilities. A possible explanation of this result is the fact that entrepreneurial skills are related with sensing, seizing, and transforming, especially in the IT industry these are the necessary qualities for an individual to attain and sustain dynamic capabilities [47]. Further, dynamic capabilities are also impacted from professionals' business skills. The importance of business skills, in IT professionals training and the IT industry [49] are widely accepted; business fundamentals like leadership, collaboration, communication skills as well as the evaluation of business performance [52], are also associated with firm's dynamic capabilities base. Finally, IT professionals who contribute towards enhancing a firms' dynamic capabilities have high perceived work performance. The possible reason is that the IT professionals and its ability to transform is the most critical resource in an IT firm [43], thus the dynamic capability of IT professional, which can be defined as their ability to integrate, build, and reconfigure competencies in rapidly changing environments [46], is naturally connected with performance and competitive advantage. Previous studies (e.g. [10, 54]) have also identified the central role of dynamic capabilities in competitive advantage and 
performance (as a mediator). Therefore, the results show that data analytics, entrepreneurial and business skills of the IT professional are all important in developing the IT capabilities, and ultimately make them feel confident and productive (perceived work performance).

\subsection{Implications}

In the IT industry, in order to develop innovative and high quality products and services, solid skills, knowledge, ability and talent is required from the IT professionals. Previous research in the IT related firms emphasized that, user systems need continues change and involvement, focusing in contemporary developments and needs [53]. This leads firms to look for state-of-the-art skills for their IT professionals, in order to be able to design and implement innovative IT products and services for their organization. This is the lynchpin for IT professionals in order to successfully serve their organization, by gaining a sustainable competitive advantage for their firm. For this reason, we investigated the state-of-the-art skills through the lens of firms' evolvement and performance. The findings of this study provide several critical implications for practitioners seeking to encourage IT professionals to attain skills in relation to data analytics, entrepreneurship and business.

Following the results of this study, IT firms and IT/IS education programs can gain insight on the importance of these three skills. This will help them improve their training programs and prioritize certain elements in the development of their professionals in order to effectively support their strategies. This will lead to more efficient IT professionals, better information flow to the management level as well as more innovative and high quality IT products. This study will inform IT executives who need to know how to make the best use and selection of the available IT resources to help their firm create the competitive advantage. The foundation of the expected competitive advantage may lie on the ability of IT to support firm's strategies by allowing executives to take data-driven decisions, or by support and improving firm's business operations. This implies that IT executives must strengthen their IT professionals' set of skills. With better data analys is, entrepreneurial and business skills, IT professionals not only can be more effective in improving their relationship their colleagues or other departments of the firm and business functions, but also can further enhance the alignment between IT and business strategy.

Firms often hire IT professionals based merely on their hard skills or experience. This fully ignores the importance other equally and sometimes even more important skills (e.g., business and communication skills). Although it is difficult recognize whether a person has sufficient set of skills in data analytics, entrepreneurship and business; practitioners still must pay attention in these qualities and identify the right person who masters hard skills but is also knowledgeable if not proficient with other emerging skills, like the ones of entrepreneurship and data analysis. Furthermore, our results identified the importance of dynamic capabilities that significantly influences employees' perceived work performance. This suggests that employee's ability to transform or evolve firm's resources is well connected with his performance. This implies that IT executives must pay particular attention in the dynamic capabilities of their professionals'; both during the recruitment and training.

\subsection{Limitations}

Based on related work and 21st century technological developments, we selected to include a specific-range of state-of-the-art skills and consider their influence on IT firms. While we care-fully selected those skills, the study might have been benefited from the inclusion of some more traditional skills (e.g., traditional hard and soft skills). Moreover, there may be other predicting factors other relation-ships between them might be discovered by using a moderator. Future re-search could establish other relationships by combining the proposed model with other potential predictors; this can be addressed in a future large scale study.

Moreover, this study included only limited demographic variables (e.g., gender, experience) and due to the relative small sample size, we could not use them as control variables. Given prior research [32], individual characteristics, such as specific jobrelated skills, may result significant differences. In particular, employees who have higher levels of jobrelated skills will have a deeper understanding of the specific tasks [32]. Future research might also examine how these factors affect IT professionals' intention to learn new skills. A more detailed investigation of these skills and how these skills differ between specific department in an IT firm and their relation to firm's strategy, are also important directions for future research.

Finally, the findings are based on self-reported data. Future studies may combine self-reported data with real data from firms' performance and strategy, as well as triangulate them with more qualitative data from interviews and observations. Although, this is pioneering study, and one of the first who attempted to explain the role of 21 st century skills in IT firms. 
The collected data are from a limited number of IT professionals, from a specific country in a specific time. Thus, further research is needed, in a largescale context collecting longitudinal evidence, in order to enhance our current under-standing of the relationships among different skills and their role in diverse firms.

\subsection{Conclusions}

In this study, we proposed a theoretical model relying to DCV and 21st century skills, in order to understand whether and how a certain selection of skills influences IT professionals' capabilities and thereby their perceived performance. We conducted an empirical study and found that data analytics, entrepreneurial and business skills are critical in developing employees' ability to effectuate action that helps a firm evolve. The set with these three skills as well as the dynamic capabilities base can help firm's employees to achieve better performance, which then may lead to the competitive ad-vantage that is vital for an IT related firm which operates in such a highly competitive and continuously evolving environment.

\section{Acknowledgments}

This project has received funding from the $\mathrm{EU}$ H2020 projects No 704110 and No. 751510 and the Research Council of Norway project FUTURE LEARNING (255129/H20) and the Centre for Excellent IT Education (www.ntnu.edu/ excited).

\section{References}

[1] J. Barney, "Firm resources and sustained competitive advantage”, Journal of management, 17 (1991), pp.99-120.

[2] J. M. Becker, K. Klein, \& M. Wetzels, "Hierarchical latent variable models in PLS-SEM: guidelines for using reflective-formative type models", Long Range Planning, 45 (2012), pp. 359-194.

[3] P. Boxall, "HR strategy and competitive advantage in the service sector", Human Resource Management Journal, 13 (2003), pp. 5-20.

[4] T. Boyles, "21st century knowledge, skills, and abilities and entrepreneurial competencies: A model for undergraduate entrepreneurship education", Journal of Entrepreneurship Education, 15 (2012), pp.41-55.

[5] M. Bruhn, D. Georgi, and K. Hadwich, "Customer equity management as formative second-order construct", Journal of Business Research, 61 (2008), pp. 1292-1301.
[6] T. A. Byrd, and D. E. Turner, "An exploratory examination of the relationship between flexible IT infrastructure and competitive advantage", Information \& Management, 39 (2001), pp. 41-52.

[7] B. A. Campbell, M. Ganco, A. M. Franco, and R. Agarwal, "Who leaves, where to, and why worry? Employee mobility, entrepreneurship and effects on source firm performance", Strateg. Manag. J. 33 (2012), pp. 65-87.

[8] R. Colomo-Palacios, C. Casado-Lumbreras, E. Tovar, and P. Soto-Acosta, "A step towards human capital management in the software industry based on generic competencies", International Journal of Strategic Change Management, 3 (2011), pp. 247-259.

[9] T. H. Davenport, and D. J. Patil, "Data scientist: The sexiest job of the 21 st century", Harvard Business Review, 90 (2012), pp. 70-76.

[10] G. Di Stefano, M. Peteraf, and G. Verona, "Dynamic capabilities deconstructed: a bibliographic investigation into the origins, development, and future directions of the research domain", Industrial and Corporate Change, 19 (2011), pp. 1187-1204.

[11] A. Diamantopoulos, P. Riefler, and K. P. Roth, "Advancing formative measurement models", Journal of Business Research, 61 (2008), pp. 1203-1218.

[12] L. Edvinsson, and M. S. Malone, "Intellectual Capital: Realizing Your Company's True Value by Finding Its Hidden Roots", New York: Harper Business (1997).

[13] K. M. Eisenhardt, and J. A. Martin, "Dynamic capabilities: what are they?", Strategic management journal, 21 (2000), pp. 1105-1121.

[14] M. Entrialgo, and V. Iglesias, "The moderating role of entrepreneurship education on the antecedents of entrepreneurial intention", International Entrepreneurship and Management Journal 12 (2016), pp. 1209-1232.

[15] D. J. Finch, M. Peacock, N. Levallet, and W. Foster, "A dynamic capabilities view of employability: Exploring the drivers of competitive advantage for university graduates", Education + Training, 58 (2016), pp.61-81.

[16] K. P. Gallagher, K. M. Kaiser, J. C. Simon, C. M. Beath, and T. Goles, "The requisite variety of skills for IT professionals. Comm. of the ACM, 53 (2010), pp. 144-148.

[17] J. F. Hair, W. C. Black, B. J. Babin, and R. E. Anderson, "Multivariate data analysis: A global perspective", Pearson: Upper Saddle River, NJ (2010).

[18] J. F. Hair Jr, G. T. M. Hult, C. Ringle, and M. Sarstedt, "A primer on partial least squares structural equation modeling (PLS-SEM)”, Sage Publications (2016). 
[19] L. Hitt, F. Jin, and L. Wu, "Data Skills and Value of Social Media: Evidence from Large-Sample Firm Value Analysis”. In Proc. of ICIS (2015).

[20] J. Hulland, J, "Use of partial least squares (PLS) in strategic management research: a review of four recent studies", Strategic Management, 20 (1999), pp. 195-204.

[21] G. Kim, B. Shin, and H. G. Lee, "IT capabilities, process-oriented dynamic capabilities, and firm financial performance", Journal of the AIS, 12 (2011), pp. 487-51

[22] D. Kiron, and R. B. Ferguson, "The analytics mandate", MIT Sloan Manag. Rev., 55 (2014), pp. 1-25.

[23] M. S. Lee, et al., "Critical skills and knowledge requirements of IS professionals: A joint academic/industry investigation”. MIS Quarterly, 19 (1995), pp.313-340.

[24] I. Leftheriotis, and M. Giannakos, "Using social media for work: Losing your time or improving your work?", Computers in Human Behavior, 31 (2014), pp. 134-142.

[25] R. L. Leitheiser, "MIS skills for the 1990s: A survey of MIS managers' perceptions", Journal of Management Information Systems, 9 (1992), pp. 69-91.

[26] Y. Lin, and L. Y. Wu, "Exploring the role of dynamic capabilities in firm performance under the resource-based view framework", J. Bus. Res., 67 (2014), pp. 407-413.

[27] F. Linan, "Skill and value perceptions: how do they affect entrepreneurial intentions?", Int. Entrepreneursh. Manag. J., 4 (2008), pp. 257-272.

[28] J. Luftman, and E. Henrique, "Key issues for IT executives 2008”, MIS Quarterly, 8 (2009), pp. 151-159.

[29] S. B. MacKenzie, et al., "The problem of measurement model misspecification in behavioral and organizational research and some recommended solutions", Journal of Applied Psychology, 90 (2005), pp. 710-730.

[30] A. Malhotra, S. Gosain, and O. Sawy, "Absorptive capacity configurations in supply chains: gearing for partner-enabled market knowledge creation", MIS quarterly, 29 (2005), pp. 145-187.

[31] Mikalef, P., \& Pateli, A. (2017). Information technology-enabled dynamic capabilities and their indirect effect on competitive performance: Findings from PLSSEM and fsQCA. Journal of Business Research, 70, 1-16.

[32] F. P. Morgeson, et al., "The importance of job autonomy, cognitive ability, and job-related skill for predicting role breadth and job performance", Journal of Applied Psychology, 90 (2005), pp. 399-406.

[33] S. Petter, D. Straub, and A. Rai, "Specifying formative constructs in information systems research", MIS Quarterly, 31 (2007), pp.623-656.
[34] R. S. Poston, and J. Dhaliwal, "IS Human Capital: Assessing Gaps to Strengthen Skill and Competency Sourcing", Communic. of the AIS, 36 (2015), artic. 34.

[35] D. J. Power, 'Using 'Big Data' for analytics and decision support”, J. Decis. Syst., 23 (2014), pp. 222-228.

[36] C. M. Ringle, M. Sarstedt, and D. W. Straub, "Editor's comments: a critical look at the use of PLS-SEM in MIS quarterly”, MIS Quarterly, 36 (2012), pp. iii-xiv.

[37] J. G. Rivera-Ibarra, J. Rodríguez-Jacobo, J., M. A. Serrano-Vargas, "Competency framework for software engineers", In the 23rd IEEE CSEE\&T (2010), pp. 33-40.

[38] N. Roberts, and J. Thatcher, "Conceptualizing and testing formative constructs: tutorial and annotated example", ACM SIGMIS Database, 40 (2009), pp. 9-39.

[39] R. P. Rumelt, "How much does industry matter?", Strategic Management Journal, 12 (1991), pp. 167-185.

[40] M. Sahami, A. Danyluk, S. Fincher, K. Fisher, K., et al. "Computer Science Curricula 2013: Curriculum Guidelines for Undergraduate Degree Programs in Computer Science”, ACM-IEEE Computer Society, (2013)

[41] S. Salunke, J. Weerawardena, and J. R. McCollKennedy, "Competing through service innovation: The role of bricolage and entrepreneurship in project-oriented firms", J. Bus. Res, 66 (2013), pp. 1085-1097.

[42] V. Sambamurthy, A. Bharadwaj, and V. Grover, "Shaping agility through digital options: Reconceptualizing the role of information technology in contemporary firms. MIS Quarterly, 27 (2003), pp. 237-26

[43] R. Saraswathy, et al. "Facades of attractive employer in Indian it industry: Existing employee perspective", Int. J. Hum. Cap. Inf. Technol. Prof., 2 (2011), pp. 80-98.

[44] R. F. Scherer, J. D. Brodzinsky, and F. A. Wiebe, "Examining the Relationship between Personality and Entrepreneurial Career Preference", Entrepreneurship and Regional Development, 3 (1991), pp. 195-206.

[45] P. P. Tallon, "Inside the adaptive enterprise: an information technology capabilities perspective on business process agility", IT and Management, 9 (2008), pp. 21-36.

[46] D. J. Teece, "Explicating dynamic capabilities: the nature and microfoundations of (sustainable) enterprise performance", Strateg. manag. J. 28 (2007), pp. 1319-1350.

[47] D. J. Teece, "Dynamic capabilities: Routines versus entrepreneurial action”, Journal of Management Studies, 49 (2012), pp. 1395-1401.

[48] M. Tenenhaus, V. E. Vinzi, et al. "PLS path modeling", Computational statistics \& data analy sis, (2005) pp 159-205. 
[49] H. Topi, J. S. Valacich, R. T. Wright, et al. "Curriculum guidelines for undergraduate degree programs in information systems", ACM/AIS task force (2010).

[50] S. F. Wamba, A. Gunasekaran, et al. "Big data analytics and firm performance: Effects of dynamic capabilities", Journal of Business Research, 70 (2016), pp. 356-365.

[51] E. T. G. Wang, C. H. Chiu, and K. X. Chen, "Effect of IT Skills on IT Capabilities and IT-Business Alignment", In Proceedings of PACIS, Paper 113 (2013).

[52] Wang, Y., Lin, T. C. \& Tsay, C. (2016). Encouraging IS developers to learn business skills: an examination of the MARS model. IT \& People, 29(2), 381-418.
[53] K. E. Wilson, S. Vyakarnam, C. Volkmann, et al. "Educating the next wave of entrepreneurs: Unlocking entrepreneurial capabilities to meet the global challenges of the 21 st century", In World Economic Forum: A Report of the Global Education Initiative. (2009)

[54] L. Y. Wu, "Entrepreneurial resources, dynamic capabilities and start-up performance of Taiwan's high-tech firms", J. Bus. res., 60 (2007), pp. 549-555.

[55] P. L. Yu, and Y. L. Wang, "Improving IT professionals job skills development: The use of management styles and individual cultural value orientation”, Asia Pac. Manag. Rev., 21 (2016), pp.63-73.

\section{Appendix: Survey Measures Validity of Formative Constructs}

\begin{tabular}{|c|c|c|c|c|}
\hline Items/Questions & Mean-S.D. & Weight & VIF & T-S tatistics \\
\hline \multicolumn{5}{|c|}{ How do you rate yourself in the following data analy sis skills/ability sets? ( 1 - Not sufficient at all, $7-$ Highly sufficient) } \\
\hline DAS1: Big data analytics & \multirow[t]{8}{*}{$3.39-1.71$} & -0.103 & 3.015 & 0.865 \\
\hline DAS2: Data and knowledge visualization & & 0.280 & 3.117 & 1.439 \\
\hline DAS3: Statistical techniques & & 0.616 & 1.716 & 0.793 \\
\hline DAS4: Transforming raw data into business intelligence & & 0.741 & 3.343 & 0.136 \\
\hline $\begin{array}{l}\text { DAS5: Structuring and analyzing content (web-based, sensor-based) in a } \\
\text { meaningful way }\end{array}$ & & -0.831 & 2.411 & 0.444 \\
\hline DAS6: Research methods and empirical validation & & 0.406 & 1.783 & 1.117 \\
\hline DAS7: Working with high volume unstructured data & & 0.009 & 3.589 & 1.365 \\
\hline DAS8: Machine learning & & -0.220 & 1.546 & 1.044 \\
\hline \multicolumn{5}{|c|}{ How do you rate yourself in the following data analy sis skills/ability sets? ( $1-$ Not sufficient at all, $7-$ Highly sufficient) } \\
\hline ES1: Recognition of opportunity & \multirow[t]{6}{*}{$4.22-1.67$} & 0.322 & 2.623 & 1.571 \\
\hline ES2: Creativity & & 0.478 & 2.471 & 1.257 \\
\hline ES3: Problem solving skills & & 0.263 & 1.693 & 0.254 \\
\hline ES4: Leadership and communication skills & & -0.055 & 2.801 & 0.704 \\
\hline ES5: Development of new product and services & & -0.145 & 2.196 & 2.294 \\
\hline ES6: Networking skills and making professional contacts & & 0.359 & 1.865 & 1.848 \\
\hline \multicolumn{5}{|c|}{ How do you rate yourself in the following business skills/ability sets? ( $1-$ Not sufficient at all, $7-$ Highly sufficient $)$} \\
\hline BS1: Knowledge about business functions & \multirow[t]{4}{*}{$3.34-1.63$} & 0.748 & 4.996 & 2.443 \\
\hline $\begin{array}{l}\text { BS2: Interpretation of business problems and the capacity to develop } \\
\text { appropriate technical solutions }\end{array}$ & & 0.540 & 3.248 & 1.609 \\
\hline BS3: Understanding the company's policies and plans & & -0.797 & 4.459 & 0.021 \\
\hline BS4: Understanding economic facts and figures & & 0.472 & 3.369 & 0.719 \\
\hline \multicolumn{5}{|c|}{$\begin{array}{l}\text { To what extent do you believe you have contributed company-wise in the following aspects within the firm you work: }(1-\text { not at } \\
\text { all, } 7 \text { - very much) }\end{array}$} \\
\hline DC1: In acquiring and assimilating new knowledge & \multirow[t]{4}{*}{$5.23-1.39$} & 0.543 & 1.385 & 2.242 \\
\hline DC2: In exploiting opportunities & & 0.228 & 1.546 & 0.827 \\
\hline DC3: In reconfiguring existing ways of doing things & & 0.156 & 1.808 & 0.662 \\
\hline DC4: In improving coordination of activities & & 0.374 & 1.420 & 1.670 \\
\hline \multicolumn{5}{|c|}{$\begin{array}{l}\text { Please indicate the extent to which you agree or disagree with the following sentences regarding your work performance (1 - } \\
\text { strongly disagree, } 7 \text { - strongly agree) }\end{array}$} \\
\hline WP1: I almost always perform better than an acceptable level & \multirow[t]{4}{*}{$5.23-1.12$} & 0.259 & 2.210 & 5.455 \\
\hline WP2: I often perform better than can be expected from me & & 0.296 & 2.137 & 5.984 \\
\hline WP3: I often put in extra effort in my work & & 0.313 & 1.885 & 7.944 \\
\hline WP4: The quality of my work is top-notch & & 0.316 & 2.326 & 5.954 \\
\hline
\end{tabular}

